\title{
Associations between eating behaviors and muscle strength among Chinese adults: A population-based cross-sectional study
}

Liang Ding ( $\sim$ dlseu1980@163.com )

Southeast University https://orcid.org/0000-0003-3394-1424

\section{Wenbo Zhang}

Changchun Institute of Education

\section{Xijun Sun}

Huaiyin Institute of Technology

\section{Yongxiang Wang}

Huaiyin Institute of Technology

\section{Shulei Chen}

Dalian Institute of Science and Technology

\section{Research}

Keywords: eating behaviors, muscle strength, cross-sectional study, Chinese adults

Posted Date: March 18th, 2020

DOl: https://doi.org/10.21203/rs.3.rs-17700/v1

License: (9) This work is licensed under a Creative Commons Attribution 4.0 International License. Read Full License 


\section{Abstract}

Background: Poor eating behaviors are associated with imbalances in energy and food intake, which may directly or indirectly contribute to muscle strength loss. This study aimed to investigate the association between eating behaviors and muscle strength in Chinese adults.

Methods: We designed a cross-sectional study of 2,036 Chinese individuals aged 25-68 years, conducted in 2017. Eating behaviors, including breakfast consumption, snacking after dinner, and eating rate, were assessed using a self-administered questionnaire. Muscle strength was determined by grip strength and assessed using a digital grip dynamometer.

Results: After final adjustments for confounding factors, grip strength was measured as 35.2 (95\% confidence interval [Cl]: $34.6-35.8), 36.0$ (95\% Cl: $35.6-36.4)$, and 36.9 (95\% Cl: $36.6-37.2)$ for those who skipped, occasionally ate, and regularly ate breakfast, respectively ( $p$ for trend $<0.001$ ). Those who always, sometimes, and seldom snacked after dinner, respectively ( $p$ for trend $<0.001$ ), reported the following grip strength: 34.6 (95\% Cl: $33.9-35.2)$, 36.2 (95\% Cl: $35.8-36.6)$, and 36.8 (95\%Cl: $36.5-37.2)$. Significant associations were not found between eating rate and grip strength.

Conclusions: Present study showed that higher frequency of breakfast consumption and lower frequency of snacking after dinner were associated with better muscle strength in Chinese adults. Therefore, eating behaviors may be involved in muscle function.

\section{Background}

The age-associated loss of skeletal muscle mass [1], called sarcopenia, has been postulated as a major factor in the decline of strength with aging [2]. Poor muscle strength is related to functional impairment [3], disability [4], falls [5], loss of independence, and mortality [6-8] in older adults. In addition, a six-year follow-up study has demonstrated that, even in middle-aged individuals, the risk of mortality in those with lower grip strength is more than twice that of those with higher grip strength [9]. Therefore, preventing muscle strength decline is important for well-being.

Meanwhile, eating behaviors are critical human health, associated with many health outcomes. In a Japanese study, people with more than two unhealthy eating behaviors have shown a higher incidence of depressive symptoms compared with those with fewer than two unhealthy eating behaviors [10]. In a different study, self-reported eating rate is positively associated with the presence of metabolic syndrome in Japanese men and women [11]. Other studies have also shown that night eating can cause nutritional imbalance [12], and compared with irregular breakfast consumption, regular breakfast consumption contributes to higher nutrient intake, such as dietary fiber, iron, calcium, and folate [13]. As such, night eating and irregular breakfast consumption may contribute to muscle strength decrease owing to nutrient imbalance; indeed, nutrient deficiency is a well-known predictor of muscle strength loss [14]. A high frequency of breakfast consumption is also associated with high physical activity (PA) $[15,16]$, which can improve muscle strength and prevent strength loss. Based on these findings, it is possible that eating 
behaviors may affect muscle function. However, few studies have directly examined the relation between eating behaviors and muscular function. A population-based study has indicated that an increase in the components of unhealthy eating habits is associated with poor aerobic fitness and lower limb muscle power in primary school children [17]. In addition, breakfast consumption frequency has been associated with muscle strength and physical fitness in Japanese adults[18] and Chinese university students [19]. However, the association between snacking after dinner, eating rate, frequency of breakfast (three representative eating behaviors), and muscular strength in Chinese adults is unclear. Therefore, we designed a cross-sectional study to investigate whether eating behaviors would be associated with muscle strength in Chinese adults.

\section{Methods}

\section{Participants}

The present study used 2017 data from an annual health examination for adult employees conducted with self-report questionnaires in Pingfang District, Haerbin, China. In this study, 2,323 participants provided their written informed consent for the analysis of their data. The protocol for the study was approved by the Human Investigation Ethics Committee of Huaiyin Institute of Technology.

Responses were excluded if the data for grip strength $(n=98)$, eating behaviors $(n=30)$, depressive symptoms $(n=156)$, and PA $(n=3)$ were missing. The final study population consisted of 2,036 participants $($ men $=1,191$, women $=845)$.

\section{Eating Behaviors}

Eating behaviors were measured using a self-administered questionnaire that included items on breakfast consumption, snacking after dinner, and eating rate. Frequency of breakfast consumption was determined by the question, "In past month, how many times did you eat breakfast per week?" Snacking after dinner was determined by the question, "In past month, how many days did you snack after dinner?" Participants were asked to report the frequency of their breakfast consumption and snacking after dinner by responding with "never," "once per week," to "7 times per week." Regarding breakfast consumption, the participants were categorized as regular consumers (6-7 times per week), occasional consumers (2-5 times per week), and skippers (less than two times per week). Regarding snacking after dinner, participants were categorized as "always" (6-7 times per week), "sometimes" (2-5 times per week), and "seldom" (less than two times per week). Eating rate was examined using the following question: How quickly do you eat? The participants responded by choosing from the following five categories: very slowly, relatively slowly, at a moderate speed, relatively quickly, and very quickly. We combined the very slow and relatively slow categories to form one slow category, and the fast and relatively fast categories to form one fast category. 


\section{Muscle Strength}

Muscle strength was determined by handgrip strength and measured using a digital grip dynamometer (WCS-100 Qishu Co., Shanghai, China), with participants in the standing position. The dynamometer was adjusted to fit participants' individual hand sizes. The participants were encouraged to exert maximal grip effort. Grip strength was measured four times: twice for each hand on an alternating basis, with brief intervals between trials. The average value of the highest power recorded for both hands was included in the analysis $[20,21]$.

\section{Confounding Variables}

Blood pressure (BP) was measured twice using an automatic device, which was applied to the upper-left arm (KENTAROU HBP-9021; OMRON Co., Ltd., Japan) subsequent to rest periods of five minutes in the sitting position. The mean of two measurements was used as the BP value. Hypertension was determined based on a systolic BP of $\geq 140 \mathrm{mmHg}$, diastolic BP of $\geq 90 \mathrm{mmHg}$, or use of antihypertensive medication [22]. Diabetes was determined based on a fasting blood glucose concentration of $\geq 126 \mathrm{mg} / \mathrm{dL}$ or use of antidiabetic medication. Depressive symptoms were assessed using the Chinese version of the Self-Rating Depression Scale (SDS) [23]. An SDS score of $\geq 45$ was adopted as the cutoff point indicating relatively mild or severe depressive symptoms [24]. Body mass index (BMI) was calculated as weight/height ${ }^{2}\left(\mathrm{~kg} / \mathrm{m}^{2}\right)$. Educational level was assessed by determining the highest school grade completed, and classified into two categories: < college or $\geq$ college. Occupation was classified into two categories: desk work or other. Information regarding age, sex, smoking status, drinking status, occupation, and living status was obtained via a questionnaire survey. Levels of daily PA were estimated using the International Physical Activity Questionnaire (IPAQ). Total daily PA (metabolic equivalents [METs] in h/week) was calculated [25]. PA was categorized into high and low categories.

\section{Statistical analysis}

Descriptive data are presented as means (with 95\% confidence intervals [95\%Cls]) and percentages. Grip strength was used as a dependent variable, whereas categories of eating behaviors (all in tertiles) were used as independent variables. Differences between eating behavior categories were examined using analysis of variance for continuous variables and logistic regression analysis for proportional variables. An analysis of covariance was performed to examine the correlation between eating behaviors and grip strength in the crude and adjusted models. Model 1 was adjusted for age, sex, and BMI, whereas Model 2 was adjusted for the items in Model 1, as well as hypertension, diabetes, and depressive symptoms. Model 3 was adjusted for the items in Models 1 and 2, as well as PA, education level, occupation, living status, smoking, and drinking habits. Bonferroni-corrected $p$ values were used to compare differences between groups. All statistical analyses were performed using SPSS Statistics version 24.0 for Windows (SPSS, Inc., Chicago, IL). Means and 95\%Cls were reported throughout. All p values for linear trends were 
calculated using the categories described above; a p value of $<0.05$ was considered statistically significant.

\section{Results}

The study participants' characteristics according to eating behaviors are presented in Table 1. As eating rate increased, the proportion of obesity increased, whereas the proportion of those with a higher educational level and reported drinking alcohol occasionally decreased significantly ( $p$ for trend $<0.05$ ). As frequency of breakfast consumption increased, the proportion of men, aged $<40$ years, living alone, and with depressive symptoms decreased, whereas the proportion of those aged $>50$ years, with higher PA, and with a smoking habit increased significantly ( $p$ for trend $<0.001$ ). The proportion of participants whose age was $<40$ years or classified as obese was significantly lower across the categories of snacking after dinner ( $\mathrm{p}$ for trend $<0.05$ ). The proportion of participants aged $40-49$ years, with a normal body weight, lower educational level, job as a desk worker, or with diabetes was significantly lower across the categories of snacking after dinner $(p$ for trend $<0.05$ ). No significant association was observed between other characteristics and eating behavior. 
Table 1

Participant characteristics according to eating behaviorsa.

\begin{tabular}{|c|c|c|c|c|c|c|}
\hline & \multicolumn{2}{|c|}{ Eating rate } & \multicolumn{2}{|c|}{ Breakfast consumption } & \multicolumn{2}{|c|}{ Snacking after dinner } \\
\hline & Slow & Fast & Skipper & Consumer & Seldom & Always \\
\hline \multicolumn{7}{|l|}{$\mathrm{n}$} \\
\hline Sex (men; \%) & 59.9 & 63 & 69.1 & $57.6^{\star \star}$ & 59.6 & 56.4 \\
\hline \multicolumn{7}{|l|}{ Age (years) } \\
\hline$<40$ & 40.3 & 44.9 & 48.1 & $35.2^{\star \star \star}$ & 36.6 & $56.7^{\star \star \star}$ \\
\hline $40-49$ & 26.9 & 24.9 & 28 & 25.6 & 30.3 & $20.4^{\star \star \star}$ \\
\hline$>50$ & 32.8 & 30.2 & 23.9 & $39.2^{\star \star \star}$ & 33.1 & 22.8 \\
\hline \multicolumn{7}{|l|}{$\operatorname{BMI}\left(\mathrm{kg} / \mathrm{m}^{2}\right)^{\mathrm{b}}$} \\
\hline$\leq 18.5$ & 8.1 & 9.8 & 7.8 & 7.7 & 7.4 & 9.7 \\
\hline $18.6-24.0$ & 57 & 51.5 & 61 & 59.1 & 59.4 & $48.4^{*}$ \\
\hline $24.1-28.0$ & 26.6 & 24.6 & 24.5 & 23.6 & 24 & 25.3 \\
\hline$>28$ & 8.3 & $14.1^{\star}$ & 6.7 & 9.5 & 9.2 & $16.6^{*}$ \\
\hline PA high (METs h/week; \%) & 48.9 & 49.5 & 43.5 & $53.1^{\star \star}$ & 49.5 & 48.4 \\
\hline Education level $\geq 12$ years (\%) & 27.8 & $21.6^{\star \star}$ & 22.6 & 21.9 & 25.7 & $21.8^{*}$ \\
\hline Occupation (desk work; \%) & 42.0 & 42.6 & 46.8 & 42.6 & 44 & $38.1^{\star}$ \\
\hline Living along (\%) & 22.4 & 26.9 & 26.3 & $20.3^{*}$ & 23.2 & 27 \\
\hline \multicolumn{7}{|l|}{ Smoking status (\%) } \\
\hline Smoker & 47.3 & 42.6 & 34.9 & $51.8^{\star \star \star}$ & 48.3 & 47.8 \\
\hline \multicolumn{7}{|l|}{ Drinking status (\%) } \\
\hline Drinking everyday & 21.6 & 24.6 & 26.9 & 23.5 & 21.8 & 19.4 \\
\hline Drink occasionally & 52.9 & $45.9^{*}$ & 50 & 47.7 & 50 & 55 \\
\hline No drinking & 25.5 & 29.5 & 23.1 & 28.8 & 28.3 & 25.6 \\
\hline Hypertension (\%) & 22.6 & 21.6 & 24.2 & 24.7 & 22.7 & 19.7 \\
\hline Diabetes (\%) & 5.8 & 5.2 & 5.1 & 6.4 & 6.2 & $2.8^{*}$ \\
\hline
\end{tabular}




\begin{tabular}{|c|c|c|c|c|c|c|}
\hline \multirow[b]{2}{*}{ Depressive symptom (\%) } & \multicolumn{2}{|c|}{ Eating rate } & \multicolumn{2}{|c|}{ Breakfast consumption } & \multicolumn{2}{|c|}{ Snacking after dinner } \\
\hline & 30.6 & 33.4 & 37.1 & $28.3^{\star \star \star}$ & 31.5 & 30.1 \\
\hline \multicolumn{7}{|c|}{ a Obtained using $x^{2}$ test for proportional variables. } \\
\hline \multicolumn{7}{|c|}{ b BMI: body mass index; PA: physical activity. } \\
\hline \multicolumn{7}{|c|}{$* p$ for trend $<0.05, * *<0.01, * \star *<0.001$} \\
\hline
\end{tabular}

Table 2 shows the adjusted association between eating behaviors and grip strength. In the unadjusted model, grip strength ( $\mathrm{kg}$ ) was measured as 37.0 (36.4-37.6), 35.9 (35.1-36.6), and 34.8 (33.6-35.9) for the seldom, sometimes, and always snacking after dinner categories, respectively ( $p$ for trend $=0.001$ ). However, no significant association was seen between breakfast consumption, eating rate, and grip strength. After the final adjustment (Model 3), significantly positive association was found between breakfast consumption and grip strength. Grip strength was higher across the categories of breakfast consumption: $35.2(34.6,35.8), 36.0(35.6,36.4)$, and $36.9(36.6,37.2)$ for the skipper, occasional consumer, and regular consumer categories, respectively ( $p$ for trend $<0.001$ ). Grip strength was higher in the regular consumer category relative to the occasional consumer and skipper categories (Bonferronicorrected $p<0.05$ ). The inverse association between snacking after dinner and grip strength was consistent in the final adjusted model (Model 3 ) ( $p$ for trend $<0.001$ ). Grip strength was lower in the always category relative to the sometimes and seldom categories (Bonferroni-corrected $p<0.05$ ). In addition, significant difference was found between the sometimes and seldom categories (Bonferronicorrected $p<0.05$ ). Finally, eating rate was not significantly associated with grip strength in Models 1,2 , and 3 . 
Table 2

Adjusted relationship between eating behaviors and grip strength $(\mathrm{kg}) \mathrm{a}$.

\begin{tabular}{|c|c|c|c|c|c|}
\hline & & Unadjusted & Model $1^{\text {b }}$ & Model $2^{c}$ & Medel $3^{d}$ \\
\hline \multicolumn{6}{|c|}{$\begin{array}{l}\text { Breakfast } \\
\text { consumption }\end{array}$} \\
\hline Skipper & $\begin{array}{l}(n= \\
372)\end{array}$ & $\begin{array}{l}37.1(36.1, \\
38.2)\end{array}$ & $\begin{array}{l}35.2(34.7 \\
35.8)\end{array}$ & $\begin{array}{l}35.2(34.6 \\
35.8)\end{array}$ & $\begin{array}{l}35.2(34.6 \\
35.8)\end{array}$ \\
\hline $\begin{array}{l}\text { Occasional } \\
\text { consumer }\end{array}$ & $\begin{array}{l}(n= \\
615)\end{array}$ & $\begin{array}{l}35.3(34.5 \\
36.1)^{f}\end{array}$ & $\begin{array}{l}36.0(35.5 \\
36.4)\end{array}$ & $\begin{array}{l}36.0(35.5 \\
36.4)\end{array}$ & $\begin{array}{l}36.0(35.6 \\
36.4)\end{array}$ \\
\hline Consumer & $\begin{array}{l}(n= \\
1049)\end{array}$ & $\begin{array}{l}36.6(36.0 \\
37.3)^{\mathrm{g}}\end{array}$ & $\begin{array}{l}36.9(36.6 \\
37.2)^{f, g}\end{array}$ & $\begin{array}{l}36.9(36.6 \\
37.3)^{f, g}\end{array}$ & $\begin{array}{l}36.9(36.6, \\
37.2)^{f, g}\end{array}$ \\
\hline p for trend ${ }^{e}$ & & 0.403 & $<0.001$ & $<0.001$ & $<0.001$ \\
\hline \multicolumn{6}{|c|}{$\begin{array}{l}\text { Snacking after } \\
\text { dinner }\end{array}$} \\
\hline Seldom & $\begin{array}{l}(n= \\
1057)\end{array}$ & $\begin{array}{l}37.0(36.4 \\
37.6)\end{array}$ & $\begin{array}{l}36.8(36.5 \\
37.2)\end{array}$ & $\begin{array}{l}36.9(36.5 \\
37.2)\end{array}$ & $\begin{array}{l}36.8(36.5 \\
37.2)\end{array}$ \\
\hline Sometimes & )$^{(n=690}$ & $\begin{array}{l}35.9(35.1 \\
36.6)^{f}\end{array}$ & $\begin{array}{l}36.2(35.8 \\
36.7)\end{array}$ & $\begin{array}{l}36.2(35.8 \\
36.7)\end{array}$ & $\begin{array}{l}36.2(35.8, \\
36.6)^{f}\end{array}$ \\
\hline Always & )$^{(n=289}$ & $\begin{array}{l}34.8(33.6 \\
35.9)^{f}\end{array}$ & $\begin{array}{l}34.6(33.9 \\
35.2)^{f, g}\end{array}$ & $\begin{array}{l}34.5(33.9 \\
35.2)^{f, g}\end{array}$ & $\begin{array}{l}34.6(33.9, \\
35.2)^{f, g}\end{array}$ \\
\hline$p$ for trend ${ }^{e}$ & & 0.001 & $<0.001$ & $<0.001$ & $<0.001$ \\
\hline \multicolumn{6}{|l|}{ Eating rate } \\
\hline Slow & $\begin{array}{l}(n= \\
695)\end{array}$ & $\begin{array}{l}36.6(35.9 \\
37.4)\end{array}$ & $\begin{array}{l}36.4(36.0 \\
36.8)\end{array}$ & $\begin{array}{l}36.4(36.0 \\
36.8)\end{array}$ & $\begin{array}{l}36.4(36.0 \\
36.8)\end{array}$ \\
\hline Medium & $\begin{array}{l}(n= \\
1036)\end{array}$ & $\begin{array}{l}36.0(35.4 \\
36.6)\end{array}$ & $\begin{array}{l}36.4(36.1 \\
36.8)\end{array}$ & $\begin{array}{l}36.4(36.1 \\
36.8)\end{array}$ & $\begin{array}{l}36.4(36.1 \\
36.8)\end{array}$ \\
\hline Fast & $\begin{array}{l}(n= \\
305)\end{array}$ & $\begin{array}{l}36.7(35.6 \\
37.9)\end{array}$ & $\begin{array}{l}35.8(35.2 \\
36.4)\end{array}$ & $\begin{array}{l}35.8(35.2 \\
36.4)\end{array}$ & $\begin{array}{l}35.8(35.2 \\
36.4)\end{array}$ \\
\hline p for trend ${ }^{e}$ & & 0.889 & 0.128 & 0.12 & 0.132 \\
\hline \multicolumn{6}{|c|}{${ }^{a}$ Variables are expressed as estimated geometrics means $(95 \% \mathrm{Cl})$. } \\
\hline \multicolumn{6}{|c|}{ b Adjusted for age, sex, and body mass index. } \\
\hline \multicolumn{6}{|c|}{${ }^{\mathrm{C}}$ Further adjusted for hypertension, diabetes, and depressive symptoms. } \\
\hline
\end{tabular}


e Obtained using ANCOVA.

${ }^{f}$ Significantly different to the first category, $p<0.05$ (Bonferroni-corrected).

g Significantly different to the second category, $p<0.05$ (Bonferroni-corrected).

\section{Discussion}

This study showed that a high frequency of breakfast consumption and low frequency of snacking after dinner were significantly associated with higher grip strength in Chinese adults aged 25-68 years. We considered various confounding factors, including age, sex, BMI, health status, and lifestyle. However, subsequent to adjustment for these confounding factors, the significant association between eating behaviors and grip strength remained, indicating that such a correlation was independent of these factors.

A Japanese study has shown a significant association between higher breakfast consumption and higher grip strength among 1,415 Japanese adults aged 19-83 years [18]. A Chinese study has also indicated that frequent breakfast consumption is significantly associated with higher grip strength and faster sprint times in 10,125 college students [19]. Despite the difference in samples, these previous studies are consistent with the present findings. In contrast, our results are inconsistent with a European study that reported that breakfast consumption is not significantly associated with muscular fitness and speed/agility, only cardiorespiratory fitness, in 2,148 European adolescents aged 12.5-17.5 years [26]. The different methods used to assess breakfast consumption and muscle strength or different ages may explain the contrast in findings. Notably, many studies have focused on children and adolescents, whereas those on adults' eating behaviors and muscle function are scarce. We could not find any previous study that has investigated the association between night eating, eating rate, and muscle function.

To the best of our knowledge, this study is the first to demonstrate an association between self-reported eating behaviors and muscle strength in Chinese adults. There are several possible explanations for the observation of a relation between eating behaviors and grip strength. First, our primary hypothesis was that eating behaviors would exert a beneficial influence on muscle strength, as regular breakfast consumption would lead to higher nutrient intake [13] and higher energy intake [16]. Nutrient and energy intake is positively associated with muscle strength [27]. As such, regular breakfast consumption could be associated with higher muscle strength. In addition, night eating is not only reported to cause nutritional imbalance but also associated with poor sleep quality [28], which is related with poor muscle strength [29]. This link can also explain why eating behaviors are associated with muscle strength.

We also hypothesized that eating behaviors may have a beneficial effect on the prevention of muscle strength loss via high PA. The results of our study showed that a higher frequency of breakfast 
consumption is significantly associated with higher PA, in line with the results of a previous study [30]. However, the association between eating behaviors and muscle strength did not change after adjusting for PA. Thus, the relation between eating behaviors and muscle strength cannot be attributable to PA. Meanwhile, previous studies have indicated that eating rate is associated with many health behaviors and health outcomes [31,32]. However, in the present study, we did not find any significant association between eating rate and muscle strength.

The present study was subject to certain limitations. First, eating behaviors were self-reported, a method that is vulnerable to recall bias. Second, the cross-sectional design prevented causal inference regarding whether healthy eating behaviors contributed to higher grip strength or participants with higher grip strength simply tended to eat healthier relative to those with lower grip strength. Therefore, prospective or intervention studies are required to determine the causal relation between eating behaviors and grip strength. Finally, although we adjusted for a considerable number of confounding factors, we could not exclude the possibility that other covariates may have mediated the association between eating behaviors and grip strength.

The results of this study indicated that grip strength was lower in Chinese adults who skipped breakfast relative to those who regularly had breakfast, and who always snacked after dinner relative to those who sometimes and seldom snacked after dinner. This finding suggests that eating behaviors may be correlated with muscular function in adults. Eating behaviors are indispensable in people's daily life. Maintaining positive eating behaviors is important for human health. In future, a prospective study or randomized trial may confirm these findings and clarify causality.

\section{Abbreviations}

PA: Physical activity; BMI: Body mass index; BP: Blood pressure; SDS: Self-rating depression scale; IPAQ: International physical activity questionnaire; METs: Metabolic equivalents; Cls: Confidence intervals; SPSS: Statistical product and service solutions.

\section{Declarations}

\section{Acknowledgements}

We thank all participants and the Yongkang Medical Examination and Health Monitoring Center for the possibility to perform the study.

\section{Authors' contribution}

LD analyzed data and wrote the first draft of manuscript. YW and SC conceived and designed the study. WZ and XS collected data. The interpretation, wording, and revision for this manuscript was approved by 
all authors

\section{Availability of data and materials}

The dataset used and analyzed during the current study are available from the corresponding author on reasonable request.

\section{Ethics approval and consent to participate}

In this study, participants provided their written informed consent for the analysis of their data. The protocol for the study was approved by the Human Investigation Ethics Committee of Huaiyin Institute of Technology.

\section{Funding:}

This research did not receive any specific grant from funding agencies in the public, commercial, or notfor-profit sectors.

\section{Consent for publication}

Not applicable

\section{Conflicts of interest:}

There are no conflicts of interest to disclose.

\section{Author details}

${ }^{1}$ Department of Physical Education, Southeast University, Nanjing, China. ${ }^{2}$ Department of Physical Education, Changchun Institute of Education, Changchun, China. ${ }^{3}$ Department of Physical Education, Huaiyin Institute of Technology, Huaian, China. ${ }^{4}$ Department of Physical Education, Dalian Institute of Science and Technology, Dalian, China.

\section{References}


1. Harris T Muscle mass and strength: relation to function in population studies. J Nutr. 1997; 127:1004S-6S.

2. Kamel HK Sarcopenia and aging. Nutr Rev. 2003; 61:157-67.

3. Visser M, Kritchevsky SB, Goodpaster BH, Newman AB, Nevitt M, Stamm E et al. Leg muscle mass and composition in relation to lower extremity performance in men and women aged 70 to 79: the health, aging and body composition study. J Am Geriatr Soc. 2002; 50:897-904.

4. Rantanen T, Guralnik JM, Foley D, Masaki K, Leveille S, Curb JD et al. Midlife hand grip strength as a predictor of old age disability. JAMA. 1999; 281:558-60.

5. Lord SR, Ward JA, Williams P, Anstey KJ Physiological factors associated with falls in older community-dwelling women. J Am Geriatr Soc. 1994; 42:1110-7.

6. Metter EJ, Talbot LA, Schrager M, Conwit R Skeletal muscle strength as a predictor of all-cause mortality in healthy men. J Gerontol A Biol Sci Med Sci. 2002; 57:B359-65.

7. Katzmarzyk PT, Craig CL Musculoskeletal fitness and risk of mortality. Med Sci Sports Exerc. 2002; 34:740-4.

8. Newman AB, Kupelian V, Visser M, Simonsick EM, Goodpaster BH, Kritchevsky SB et al. Strength, but not muscle mass, is associated with mortality in the health, aging and body composition study cohort. J Gerontol A Biol Sci Med Sci. 2006; 61:72-7.

9. Fujita Y, Nakamura Y, Hiraoka J, Kobayashi K, Sakata K, Nagai M et al. Physical-strength tests and mortality among visitors to health-promotion centers in Japan. J Clin Epidemiol. 1995; 48:1349-59.

10. Huang C, Momma H, Cui Y, Chujo M, Otomo A, Sugiyama S et al. Independent and combined relationship of habitual unhealthy eating behaviors with depressive symptoms: A prospective study. J Epidemiol. 2017; 27:42-7.

11. Nagahama S, Kurotani K, Pham NM, Nanri A, Kuwahara K, Dan M et al. Self-reported eating rate and metabolic syndrome in Japanese people: cross-sectional study. BMJ Open. 2014; 4:e005241.

12. Kim M, Jeong E, Kim E, Cho H, Bae Y, Choi M Night eating status of university students in partial area of Chungnam. J East Asian Soc Diet Life. 2011; 21:563-76.

13. Uzhova I, Mullally D, Penalvo JL, Gibney ER Regularity of Breakfast Consumption and Diet: Insights from National Adult Nutrition Survey. Nutrients. 2018; 10.

14. Cruz-Jentoft AJ, Baeyens JP, Bauer JM, Boirie Y, Cederholm T, Landi F et al. Sarcopenia: European consensus on definition and diagnosis: Report of the European Working Group on Sarcopenia in Older People. Age Ageing. 2010; 39:412-23.

15. Julia KZ-F, Fiona BG, Peter TK, Emily FM, Stephanie TB, Catherine MC et al. Association between breakfast frequency and physical activity and sedentary time: a cross-sectional study in children from 12 countries. BMC Public Health. 2019; 19:222.

16. Yoshimura E, Hatamoto Y, Yonekura S, Tanaka H Skipping breakfast reduces energy intake and physical activity in healthy women who are habitual breakfast eaters: A randomized crossover trial. Physiol Behav. 2017; 174:89-94. 
17. Thivel D, Aucouturier J, Isacco L, Lazaar N, Ratel S, Dore E et al. Are eating habits associated with physical fitness in primary school children? Eat Behav. 2013; 14:83-6.

18. Huang C, Niu K, Momma H, Kobayashi Y, Guan L, Chujo M et al. Breakfast consumption frequency is associated with grip strength in a population of healthy Japanese adults. Nutr Metab Cardiovasc Dis. $2014 ; 24: 648-55$.

19. Cui Y, Zhang W, Gong Q, Chen Y, Chen S, Wu Z Frequency of Breakfast and Physical Fitness among Chinese College Students. Am J Health Behav. 2018; 42:156-62.

20. Huang C, Niu K, Momma H, Kobayashi Y, Guan L, Nagatomi R Inverse association between circulating adiponectin levels and skeletal muscle strength in Japanese men and women. Nutr Metab Cardiovasc Dis. 2014; 24:42-9.

21. Teraoka T Studies on the peculiarity of grip strength in relation to body positions and aging. Kobe $J$ Med Sci. 1979; 25:1-17.

22. Chaturvedi S The Seventh Report of the Joint National Committee on Prevention, Detection, Evaluation, and Treatment of High Blood Pressure (JNC 7): is it really practical? Natl Med J India. 2004; 17:227.

23. Fukuda K, Kobayashi S [A study on a self-rating depression scale (author's transl)]. Seishin Shinkeigaku Zasshi. 1973; 75:673-9.

24. Barrett J, Hurst MW, DiScala C, Rose RM Prevalence of depression over a 12-month period in a nonpatient population. Arch Gen Psychiatry. 1978; 35:741-4.

25. Bassett DR, Jr. International physical activity questionnaire: 12-country reliability and validity. Med Sci Sports Exerc. 2003; 35:1396.

26. Cuenca-Garcia M, Ruiz JR, Ortega FB, Labayen I, Gonzalez-Gross M, Moreno LA et al. Association of breakfast consumption with objectively measured and self-reported physical activity, sedentary time and physical fitness in European adolescents: the HELENA (Healthy Lifestyle in Europe by Nutrition in Adolescence) Study. Public Health Nutr. 2014; 17:2226-36.

27. Lemieux FC, Filion ME, Barbat-Artigas S, Karelis AD, Aubertin-Leheudre M Relationship between different protein intake recommendations with muscle mass and muscle strength. Climacteric. 2014; 17:294-300.

28. Stunkard AJ, Grace WJ, Wolff HG The night-eating syndrome; a pattern of food intake among certain obese patients. Am J Med. 1955; 19:78-86.

29. Chen Y, Cui Y, Chen S, Wu Z Relationship between sleep and muscle strength among Chinese university students: a cross-sectional study. J Musculoskelet Neuronal Interact. 2017; 17:327-33.

30. Corder K, van Sluijs EM, Ridgway CL, Steele RM, Prynne CJ, Stephen AM et al. Breakfast consumption and physical activity in adolescents: daily associations and hourly patterns. Am J Clin Nutr. 2014; 99:361-8.

31. Otsuka R, Tamakoshi K, Yatsuya H, Wada K, Matsushita K, OuYang P et al. Eating fast leads to insulin resistance: findings in middle-aged Japanese men and women. Prev Med. 2008; 46:154-9. 
32. Lee KS, Kim DH, Jang JS, Nam GE, Shin YN, Bok AR et al. Eating rate is associated with cardiometabolic risk factors in Korean adults. Nutr Metab Cardiovasc Dis. 2013; 23:635-41. 